\title{
Editorial
}

\section{International Conference on Electrical and Computer Engineering}

\author{
Mohammed Elmusrati, ${ }^{1}$ Ahmed Gaouda, ${ }^{2}$ Heikki Koivo, ${ }^{3}$ \\ Mohammed Buamod, ${ }^{4}$ and Saeid Belkasim ${ }^{5}$ \\ ${ }^{1}$ Communication and Systems Engineering Group, University of Vaasa, Vaasa, Finland \\ ${ }^{2}$ Department of Electrical Engineering, UAEU, Al-Ain, United Arab Emirates \\ ${ }^{3}$ Control Engineering Group, Aalto University, Espoo, Finland \\ ${ }^{4}$ Department of Electrical and Electronic Engineering, University of Benghazi, Benghazi, Libya \\ ${ }^{5}$ Department of Computer Science, Georgia State University, Atlanta, GA, USA
}

Correspondence should be addressed to Mohammed Elmusrati; moel@uwasa.fi

Received 3 November 2013; Accepted 3 November 2013

Copyright (C) 2013 Mohammed Elmusrati et al. This is an open access article distributed under the Creative Commons Attribution License, which permits unrestricted use, distribution, and reproduction in any medium, provided the original work is properly cited.

It is our great honor to introduce this conference proceeding of the first International Conference on Electrical and Computer Engineering (ICECE 2013) which had been held in Benghazi, Libya, during March 26-28, 2013.

The accepted papers in this proceeding can be divided into two tracks:

(I) power generation, control, and distribution,

(II) telecommunication electronics and signal processing.

(I) Power Generation, Control, and Distribution. ICECE 2013 papers in this track tackle renewable energy resources, power system protection, distribution systems, and power system education. For renewable energy resources, doubly fed induction generator with its $\mathrm{AC} / \mathrm{DC} / \mathrm{AC}$ converter was modeled and the nonlinear behavior in current mode controlled boost converter was analyzed in the article "Performance of control dynamics of wind turbine based on doubly fed induction generator under different modes of speed operation." A microcontroller based less switches topology and digital gating technique for controlling single-phase five-level inverters was proposed in the article "Three-year performance evaluation of single junction amorphous solar cells grid-connected power station in Libya." Challenges of developing and installing a pilot PV project to deliver AC energy to the Tripoli University electric grid were investigated in "Controlling nonlinear behavior in current mode controlled boost converter based on the monodromy matrix." In power system protection, an adaptive distance relay algorithm that can distinguish between actual faults and flow transfers was proposed in "Interfacing PMDC motor to data port of personal computer." This technique secures the required time to perform remedial controls by a defense system during cascaded events as proposed in "Prevention of cascaded events of distance relay zone three using logic controls." An on-line fuzzy logic based technique was proposed to tune the power system stabilizers and Benghazi north power plant was used as a benchmark as shown in "Performance assessment of fuzzy logic power system stabilizer on north benghazi power plant." In the area of computer-based education, interfacing PMDC Motor to data port of personal computer has been illustrated in "Microcontroller based less switches topology and digital gating technique for single-phase five-level inverter."

(II) Telecommunication Electronics and Signal Processing. ICECE 2013 papers in this track touch topics in wireless communication and signal processing. In the article "Dual analysis of the capacity of spectrum sharing cognitive radio with MRC under nakagami-m fading," both the effective and the ergodic capacities have been analyzed for cognitive radio with MRC. The obtained mathematical algorithms have been 
validated through several intensive simulations. On the other hand, the fault of mobile networks is a very critical topic. One way to expect and prevent possible faults is by analyzing the frequent huge number of alarms reported by the OMC in mobile network. In the article "Decision support system for alarm correlation in GSM networks based on artificial neural networks," the artificial neural network is proposed to recognize such alarms and provide meaningful data for the decision makers. Novel speech recognition algorithm for Arabic digits has been proposed in "Speech recognition of arabic spoken digits." After the recent war in Libya, many people lost their arms and hands. Artificial arms with the capability of an immediate respond to the brain signals (EMG) have been presented in the following promising work: "The development of body-powered prosthetic hand controlled by EMG signals using DSP processor with virtual prosthesis implementation." Last but not least, a new design of a miniature RF MEMS metal-contact switch has been presented in the article "Cantilever beam metal-contact MEMS switch."

\section{Mohammed Elmusrati Ahmed Gaouda Heikki Koivo Mohammed Buamod Saeid Belkasim}




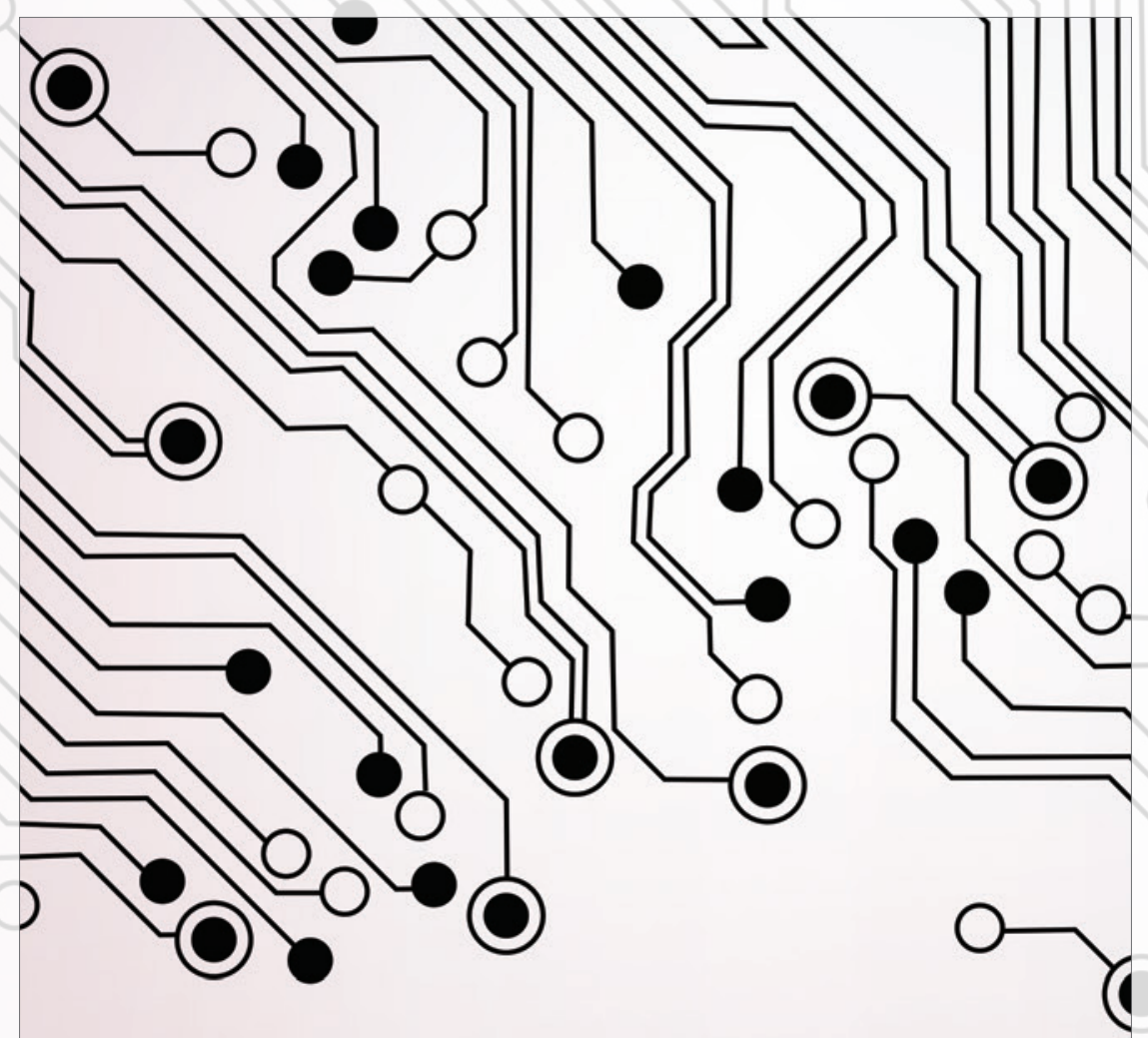

\section{The Scientific World Journal}

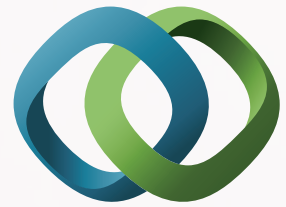

Hindawi
- Impact Factor $\mathbf{1 . 7 3 0}$

- 28 Days Fast Track Peer Review

- All Subject Areas of Science

- Submit at http://www.tswj.com 

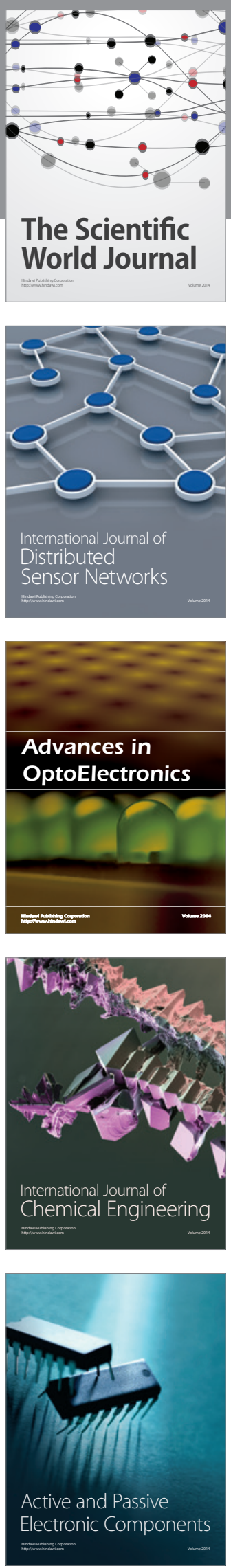
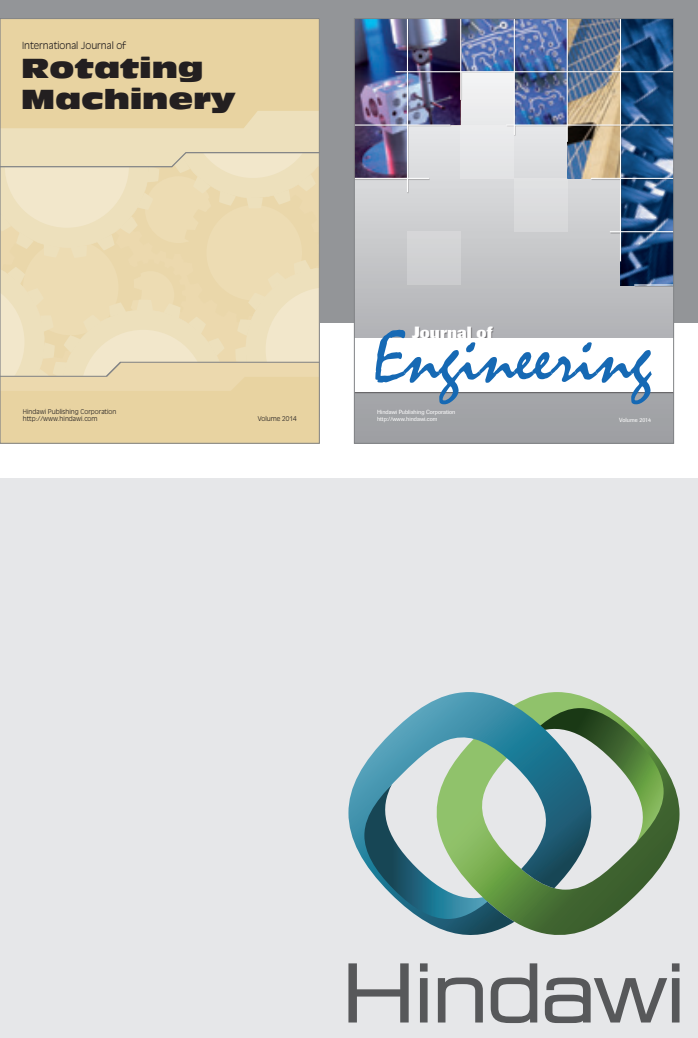

Submit your manuscripts at

http://www.hindawi.com
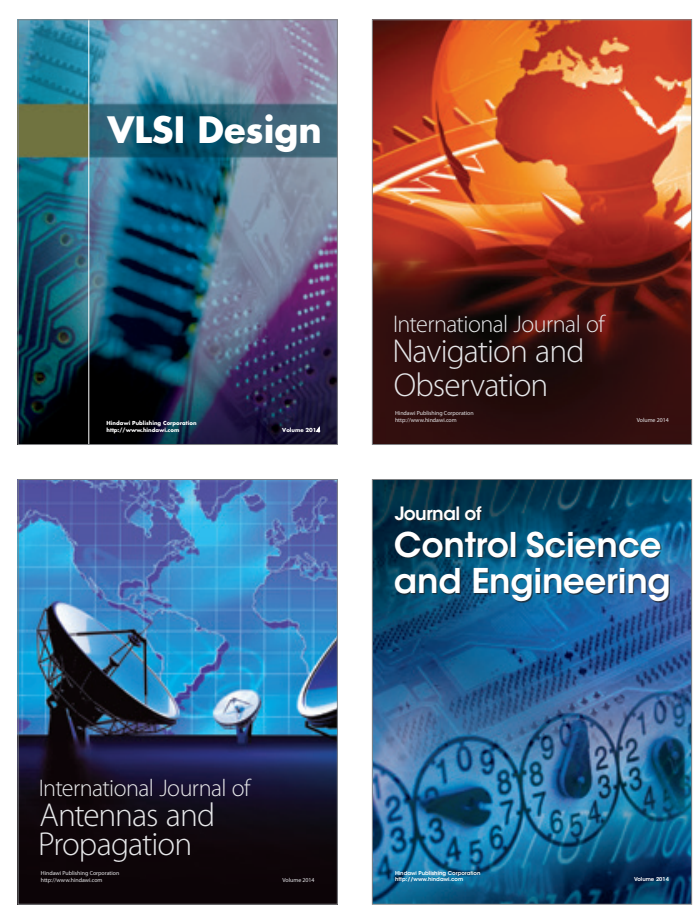
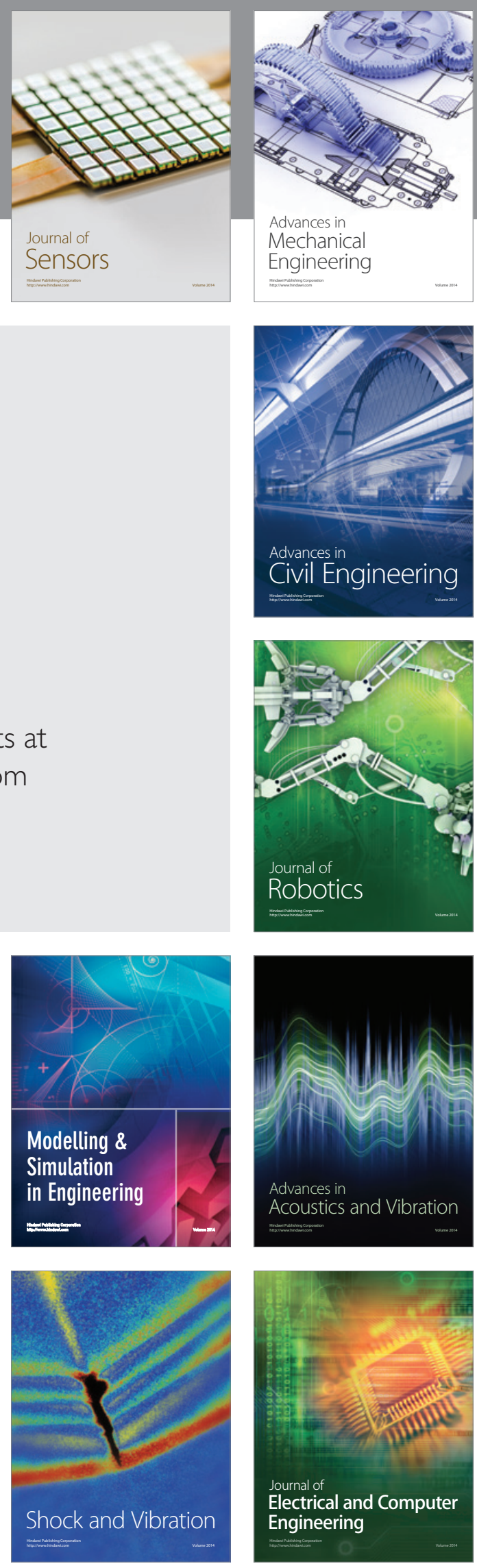